\title{
A FRAGMENTAÇÃO JURÍDICA E O DIREITO AMBIENTAL GLOBAL
}

\author{
Leandro Caletti \\ Mestre em Direito pela Faculdade Meridional (IMED). Professor da Escola de Direito (gra- \\ duação) da IMED. Professor do Programa de Pós-graduação lato sensu em Direito da IMED. \\ Membro dos grupos de pesquisas "Transnacionalismo e Circulação de Modelos Jurídicos", \\ "Ética, Cidadania e Sustentabilidade" e "Direitos Culturais e Pluralismo Jurídico", vinculados \\ ao Programa de Pós-Graduação stricto sensu em Direito da IMED. Advogado (OAB/RS). \\ E-mail: leandro.caletti@imed.edu.br
}

Márcio Ricardo Staffen

Doutor em Direito Público pela Università degli Studi di Perugia (Itália). Doutor e mestre em Ciência Jurídica pela Universidade do Vale do Itajaí (Univali). Estágio de pós-doutorado em Direito na Università degli Studi di Perugia (Bolsa CAPES/PDE 88881.120155/2016.1). Graduado em Direito pela Univali. Pesquisador do Conselho Nacional de Justiça (CNJ). Professor Permanente do Programa de Pós-graduação stricto sensu em Direito na IMED. Coordenador do Programa de Pós-Graduação Stricto Sensu em Direito (2014-2018). E-mail: marcio.staffen@imed.edu.br

\section{RESUMO}

O presente relato de pesquisa científica ostenta o objetivo geral de contextualizar a emergência de um Direito Global Ambiental no cenário de fragmentação jurídica entre normas de Direito e não-Direito. Especificamente, apresenta outros três objetivos, a saber: (1) examinar o processo de fragmentação jurídica ocasionado pela globalização e pelo transnacionalismo; (2) identificar as matrizes de Direito e de nãoDireito; e, (3) delimitar, nesse pano de fundo, o espaço de um pretenso Direito Ambiental Global. A título de problema de pesquisa, formulou-se a seguinte indagação: há espaço, no fenômeno jurídico fragmentado, para a emergência de um direito global de índole ambiental? A hipótese aventada como positiva se confirmou nas considerações finais, mormente se valendo de expedientes de soft law e autorregulação regulada. Para tanto, o estudo se valeu do método dedutivo e da pesquisa bibliográfica, da categoria e do conceito operacional como técnicas de pesquisa.

Palavras-chave: autorregulação; Direito Ambiental global; soft law. 


\section{LEGAL FRAGMENTATION AND GLOBAL ENVIRONMENTAL LAW}

\section{ABSTRACT}

The present report of scientific research has the general objective of contextualizing the emergence of a Global Environmental Law in the scenario of legal fragmentation between norms of Law and non-Law. Specifically, it has three other objectives: (1) to examine the process of legal fragmentation brought about by globalization and transnationalism; (2) identify the law and non-Law matrices; and, (3) delimit, within this background, the space of a so-called Global Environmental Law. As a research problem, the following question was formulated: Is there a space, in the fragmented legal phenomenon, for the emergence of a global right of an environmental nature? The hypothesis proposed as positive was confirmed in the final considerations, mainly using soft law cases and regulated self-regulation. For this, the study was based on the deductive method and the bibliographical research, the category and the operational concept as research techniques.

Keywords: self-regulation; global Environmental Law; soft law. 


\section{INTRODUÇÃO}

No momento presente, a fragmentação do fenômeno jurídico é uma circunstância tão notória quanto o são as suas raízes, fincadas na globalização e no transnacionalismo, cujas forças motrizes iniciais foram, respectivamente, a economia e o comércio mundial. Essa estrutura transnacional globalizada e suas práticas autorregulativas dão azo ao nascimento de regramentos sui generis, não oficiais e gestados à margem dos Estados, até então detentores do poder soberano de dizer o Direito e de livremente aplica-lo.

Assim é que, em um primeiro momento, se enfatiza as consequências da globalização e do transnacionalismo infligidas ao Estado-nação e que suprime deste último o poder de dizer o Direito com exclusividade e de aplica-lo com autonomia. Depois, constatando que a estrutura transnacional globalizada dá ensejo ao surgimento de um regramento técnico e específico não oficial, gestado à margem dos Estados, situa com precisão os cenários de Direito e de não-Direito, impulsionado, este último, pela formação de uma ordem institucional quase exclusivamente privada que se ramifica por domínios até então exclusivos dos entes estatais, infiltração que se fundamenta no seguinte raciocínio: a produção legislativa decorre diretamente da evolução social e econômica, com novas demandas e pressões políticas, técnicas, ideológicas e jurídicas, de modo que o próprio Estado acaba por aproveitar "leis privadas transnacionais" para dar-lhes aspectos estatais.

Finalizando o estudo, se identifica a soft law e a autorregulação como expedientes de Direito Ambiental Global.

\section{O PROCESSO DE FRAGMENTAÇÃO POR QUE PASSA O DIREITO}

Como já anunciado, é notório e assente que o Direito atravessa um fenômeno de fragmentação - cujas raízes estão alojadas na globalização ${ }^{1}$

1 “A globalização, processo considerado inelutável, em marcha em direção à 'sociedade aberta' ou à 'Grande Sociedade', segundo preferimos a expressão de Popper ou a de Hayek, tende - o que não se trata mais de uma descoberta - a invadir todos os espaços da vida social, econômica e política. [...] Outrora qualificadas de multinacionais, as empresas - hoje em dia transformadas em verdadeiras transnacionais - tornaram-se capazes de fazer explodir a sua produção, tendo o seu poder de negociação e de regateamento reforçados ao nível de uma economia que se tornou planetária. Atores atualmente centrais das relações econômicas globais escapam largamente à regulação tanto nacional como internacional. Uma lex mercatoria instaura-se; regras que se reclamam internacional e asseguram a promoção do livre comércio são criadas no dia a dia, impondo-se aos direitos nacionais e erigindo-se em direito 
e, consequentemente, na transnacionalidade ${ }^{2}$ do fenômeno jurídico que extrapola a tradicional polaridade nacional-internacional, tudo a demonstrar que setores sociais produzem regras com autonomia diante do Estado-nação, formando um sistema de normas sui generis.

A influência da globalização sobre o Estado e seu poder é severa, podendo-se especular que o fenômeno causou, entre os Estados mais desenvolvidos, num primeiro momento, uma expansão do caráter de organização, porquanto assumem um poder sem paralelo sobre as comunidades políticas e econômicas. Em um segundo ato, entre o resto dos Estados, o caráter e a natureza do poder estatal vão diminuir de maneira drástica. Estes Estados vazios terão autoridade prática limitada e funcionarão essencialmente como corporações com fins específicos. Terceiro, o poder se transfere à chamada esfera privada, como agente da primeira categoria de Estados e competidor com a segunda categoria, ou podem haver fusões das duas últimas - pequenos Estados e entidades privadas. Atores privados, como agentes dos grandes Estados, podem também apresentar mais poder que os pequenos Estados vazios. Quarto, a autoridade e a soberania irão se tornar mais difusas e, portanto, menos baseadas em noções tradicionais de territorialidade - para benefício dos grandes Estados, cujo status vai aumentar, e em detrimento dos outros, os Estados vazios, que tenderão a perder a coerência como atores autônomos, superiores e independentes. (BACKER, 2005, p. 266).

Como visto, o Direito, que precisa se amoldar às manifestações sociais do momento histórico, não restou indene aos influxos do processo globalizatório, seja porque tais mudanças alteraram a noção de tempo e de espaço, seja porque, de forma crucial, redefiniram a antiga identidade entre Direito e Estado.

Em síntese apertada, a globalização deu azo, por via oblíqua, a uma globalização jurídica, que atingiu em cheio a relação entre Direito

internacional do comércio. O Estado, que em princípio ainda detém o monopólio do direito, aparece como uma estrutura cada vez mais ausente quando tratamos das relações jurídicas de fato, que passam cada vez mais à margem do direito estatal". (ARNAUD, 2006, p. 18).

2 "O fenômeno da transnacionalização representa o novo contexto mundial, surgido principalmente a partir da intensificação das operações de natureza econômico-comercial no período do pós-guerra, caracterizado - especialmente - pela desterritorialização, expansão capitalista, enfraquecimento da soberania e emergência de ordenamento jurídico gerado à margem do monopólio estatal. A transnacionalização não é fenômeno distinto da globalização (ou mundialização), pois nasce no seu contexto, com características que podem viabilizar o surgimento da categoria Direito transnacional". (STELZER, 2009, p. 16). Outra matriz, no entanto, compreende o transnacionalismo como transnacionalização da litigiosidade do direito público, fenômeno que derruiria a corrente dualista do Direito Internacional. Por meio dessa prática, normas de direito internacional ou de direito transnacional seriam utilizadas em tribunais nacionais, não apenas com o intuito de obter indenizações e compensações, mas, sim, como parte de uma disputa política, que vai além da decisão do tribunal. $(\mathrm{KOH}, 1991)$. 
e Estado, tudo a demonstrar que o processo de fragmentação do Direito retira, paulatina e crescentemente, do Estado-nação o poder - até então soberano - de produzir normas de forma autônoma e executá-las. Em vista disso, afirma McGrew (1997, p. 3), quebra-se o paradigma consolidado desde a "Paz de Westphalia", que conformara o Estado sobre os pilares da soberania, territorialidade, autonomia e legalidade, dando origem, no dizer de McGrew, à "ordem internacional vestfaliana".

No dizer de Archibugi (2008, p. 55-56), a progressividade dos processos globalizatórios aumentou sobremodo a importância qualitativa e quantitativa das influências externas, modificando a forma como o poder é exercido em todos os Estados (não mais em razão cidadãos-governoEstado). As áreas em que um Estado pode tomar suas próprias decisões de forma autônoma são, portanto, cada vez mais limitadas. Ao fim e ao cabo, o Estado perdeu sua habilitação de único senhor da ordem. (ARNAUD, 2007, p. 3).

A globalização econômica, ensina Staffen (2016, p. 184), a reboque, conduz a um processo de globalização jurídica, que unifica comportamentos jurídicos e induz a circulação de modelos - mormente contratuais - previamente redigidos. Aliás, como bem anotou Cotterrell (2012, p. 340), o processo globalizatório deve ser entendido como representação física de uma interdisciplinaridade sistêmica, cujos fluxos não se restringem à economia.

Embora sustente ressalvas e objeções sobre o tema do Direito Global, Varella (2012,p.433) apresenta um quadro sintético bastante acurado para os desafios hodiernos. Segundo ele, três fenômenos demonstram a fragmentação do Direito. O primeiro, associado à multiplicação das fontes normativas que afeta um dos elementos basilares do direito internacional. O segundo, representado pela emergência de regimes privados que incide diretamente sobre o argumento da hierarquia das normas e seus meios de validação. Por último, a multiplicação de mecanismos de solução de conflitos, que expõe a condição descentralizada do poder.

Essa novel conformação dá origem a um cenário em que a normatividade se desvincula do (des)necessário elemento coercitivo que justificava a existência de um órgão de decisão centralizado.

State authority and power have become diffused in an increasingly globalized world characterized by the freer trans-border movement of people, objects and ideas. This has led some international law scholars, working from the American liberal 
tradition, to declare the emergence of a new world order based on a complex web of transgovernmental networks. (LAMBERT. 2010, p. 1).

Afigura-se inexorável, nesse cenário, redimensionar a relação entre Direito e Estado, visto que a concepção centralizada de poder, própria do Estado-nação Moderno, não é mais capaz de explicar, traduzir e aplicar a juridicidade do fenômeno transnacional, diagnóstico que é compartilhado por Habermas (2001, p. 69), para quem as funções do Estado só poderão continuar a ser preenchidas em nível parecido ao presente se passarem do Estado nacional para organismos políticos que assumam de algum modo uma economia transnacionalizada.

Esse pano de fundo desvela imperiosa a transição do Estadonacional para a era transnacional, que está fundada em: a) uma nova configuração do sistema político, e, b) na substituição da estrutura monocêntrica de poder dos Estados-nacionais por uma distribuição policêntrica de poder na qual uma grande diversidade de atores transnacionais e nacionais cooperam e concorrem entre si. (BECK, 1999, p. 27).

\section{O "DIREITO" E O "NÃO-DIREITO"}

A existência de regras que, malgrado coativas e potestativas contra os próprios entes estatais, não são produto de uma estrutura institucionalizada, verticalizada e centralizada de poder é manifesta. Esse regramento à margem do Estado é o que se convencionará chamar, aqui, de "não-Direito", sendo reservada a locução "Direito" para as normas oriundas do eixo clássico do Estado constitucional Moderno ${ }^{3}$, primeiro objeto de considerações.

A noção do que se convenciona chamar "Direito" encerra um conjunto ou sistema de normas estatais, produzidas por instâncias de representação política democrática e efetivadas por instituições estatais especializadas, com alta coordenação horizontal e integração vertical (organização burocrática). Os sujeitos são tomados, de um lado, como eleitores que delegam a produção normativa a seus representantes, e, de outro lado, como destinatários passivos das normas jurídicas, as quais

3 "Estado Constitucional Moderno deve ser entendido como aquele tipo de organização política, surgida das revoluções burguesas e norte-americana dos séculos XVIII e XIX, que tiveram como principais características a soberania assentada sobre um território, a tripartição dos poderes e a paulatina implantação da democracia representativa". (CRUZ e BODNAR, 2009, p. 56). 
são incorporadas à sua vontade por meio de comandos que determinam o conteúdo de suas condutas. Para esta concepção, enfatiza Koerner (2006, p. 150), o Direito ainda tem fronteiras nítidas, em um quádruplo sentido: 1) disciplinar, visto ser abordado teoricamente como um sistema fechado às outras formas de normatividade, às estruturas de poder e às relações sociais; 2) político, pois os momentos e modalidades de aplicação do Direito são separados dos processos de sua produção; e, 3) nacional, uma vez que o Direito é associado à soberania estatal, tornando o Estado o único produtor legítimo do Direito. Talvez se devesse acrescentar um quarto: 4) limitador, que congrega o Direito como garantia e limitação do poder (não apenas do Estado, mas de qualquer poder que oprima).

Essa conformação do Direito enquanto ordenamento jurídico calcado sobre a teoria da norma jurídica (conjunto ou sistema) tem assento histórico em duas obras clássicas do positivismo normativista, a saber, Teoria Pura do Direito, de Hans Kelsen (a segunda edição, de 1960), e Teoria do Ordenamento Jurídico, de Norberto Bobbio. É, aliás, herança positivista a pretensão de definição do Direito através da autolegitimação: é Direito aquilo produzido de acordo com regras específicas do próprio sistema, por autoridade reputada competente ou com atribuição e seguindo procedimento rígido de elaboração.

Como consectário, o cenário das fontes de produção do Direito é monopolizado pelo Estado, através dos Poderes Executivo, Legislativo e Judiciário, a quem cabe, de forma respectiva, a execução, a criação e a aplicação das regras. É, portanto, precisamente nestas últimas que se resume o Direito, estabelecidas nos códigos e leis compiladas, jamais se admitindo concepções valorativas do fenômeno jurídico e, muito menos, o recurso a fontes suprapositivas ou externas ao ordenamento. Por essa razão, o contexto de Direito exige alto grau de generalidade e de abstração, caracteres que reduzem e simplificam a matéria jurídica (utilização de poucos conceitos, mas de elevada abstração). Tem-se, então, regras jurídicas derivadas de um Poder Público, abstratas, impessoais e editadas, grosso modo, com efeitos ex nunc, tudo confluindo para a cogência e a segurança jurídica (previsibilidade do Direito), valores jurídicos principais para o modelo. Interpretar o Direito, a partir dessa estrutura, significa perquirir o significado objetivo do texto ou a vontade subjetiva do seu autor, não remanescendo espaço para discricionariedades do intérprete ou para quaisquer formas de consensualismos.

Não obstante essa concepção jurídico-doutrinária se constitua 
na mais difundida no século XX e, no que se refere às fontes do Direito, a mais desenvolvida teoricamente, importa constatar a sua superação, a reboque do esmaecimento do Estado-nação (perda do poder soberano historicamente detido de fazer e aplicar autonomamente o Direito) pelos já analisados influxos da globalização e da transnacionalidade do fenômeno jurídico. De efeito, a inadequação do cenário de Direito à nova conformação fragmentada "do Direito" representa a substituição paradigmática ${ }^{4}$ da modernidade pela pós-modernidade .

O não-Direito, de seu turno, é qualificado como a regulação oriunda - por meios coercitivos ou consensuais - de entes sem centralidade política e detenção exclusiva do poder legiferante, grosso modo privados ou sem ligação pública, que normatiza relações concretas e até pessoais de nítido caráter privado, sem desconsiderar que, por via transversa, projete efeitos em relações de direito público. No ponto, contrariamente àquilo que se poderia supor, o não-Direito não emerge apenas nas situações de lacuna ou limbo do Direito (regulamentação jurídica oficial, proveniente de um ente político centralizador que detem, de forma exclusiva, o poder legiferante), mas se produz e desenvolve à margem deste último e de forma autônoma.

Com efeito, não apenas os influxos da globalização e da transnacionalização redundaram no processo de fragmentação jurídica anunciado. A rigidez do sistema de Direito e o seu engessamento a despeito da velocidade inversamente proporcional das relações financeiras e de mercado também contribuem para a existência e o desenvolvimento do não-Direito. É também por essa carcaterística do Direito, portanto, de se manter fechado, produto de um progresso inerente ao tipo de conhecimento positivista que lhe é subjacente, homologado pela vontade nacional por meio de sua representação democrática, que surgiram e surgem, diariamente ao redor do globo, as chamadas "zonas de não-direito", em que o modo de produção legal é incapaz de acompanhar o desenvolvimento sócio-cultural

\footnotetext{
4 "[...] "paradigmas são as realizações cientificas universalmente reconhecidas que, durante algum tempo, fornece problemas e soluções modelares para uma comunidade de praticantes de uma ciência". (KUHN, 1994, p. 13).

5 "A palavra é usada, no continente americano, por sociólogos e críticos. Designa o estado da cultura após as transformações que afetaram as regras dos jogos da ciência, da literatura e das artes a partir do Século XIX. [...] considera-se pós-moderna a incredulidade em relação aos metarrelatos. É, sem dúvida, um efeito de progresso das ciências; mas este progresso, por sua vez, a supõe. Ao desuso do dispositivo metanarrativo de legitimação corresponde sobretudo a crise da filosofia metafísica e a da instituição universitária que dela dependia. [...] O saber pós-moderno não é somente o instrumento dos poderes. Ele aguça a nossa sensibilidade para as diferenças e reforça nossa capacidade de suportar o incomensurável. Ele mesmo não encontra sua razão de ser na homologia dos experts, mas na paralogia dos inventores". (LYOTARD, 2006, p. XVI-XVII).
} 
pós-moderno. (ARNAUD, 2007, p. 22-23).

O Direito, na sua autonomia, viveu e vive, desenvolveu-se e desenvolve-se também fora do cone de sombra e dos trilhos constringentes do chamado Direito oficial; consequência inevitável de não ser dimensão do poder e do Estado, mas da sociedade na sua globalidade. Não é um discurso anarquizante, mas, ou melhor, trata-se do registro daquela realidade efetiva que constitui a pluralidade dos ordenamentos jurídicos. É, no dizer de Grossi (2007, p. 67), o grande reino das liberdades do Direito, que, efetivamente, não coincide com o majestoso e reseitável ordenamento jurídico do Estado.

A essa conformação Teubner $(2005$, p. 81) denomina um "novo pluralismo jurídico", gerado independentemente do Estado, operando em várias esferas "informais" e que dá nova roupagem ao pluralismo jurídico, porquanto descobre, no lado obscuro do Direito soberano [não-Direito], o potencial subversivo dos discursos oprimidos.

The new legal pluralism moves away from questions about the effect of law on society or even the effect of society on law toward conceptualizing a more complex and interactive relationship between official and unofficial forms of ordering. Instead of mutual influences between two separate entities, this perspective sees plural forms of ordering as participating in the same social field. (MERRY, 1988, p. 873).

Nada obstante, deve ser reconhecido que a sutileza desse tangenciamento por Direito e não-Direito é acentuada, quase fluida. A ponto, por exemplo, de Teixeira e Köche (2013, p. 94) asseverarem ser bem possível, nesse cenário, se estar simplesmente descrevendo o fenômeno social ou, mesmo, abarcando normatividades morais ou consensuais. Em todo o caso, concluem, perdeu-se a noção do que é especialmente jurídico, já que não se possui mais o selo da oficialidade do Estado. Nessa quadra, cabe a pergunta: o não-Direito (espécie), afinal de contas, é Direito (gênero)? Efetivamente, sim. Um Direito "não oficial", como denomina Teubner (2005, p. 82), mas Direito.

No momento presente, estão se constituindo em "autonomia relativa" diante do Estado-nação, bem como diante da política internacional, setores distintos da sociedade mundial que produzem, a partir de si mesmos, ordenamentos jurídicos globais sui generis, como define Giddens (1991, p. 70). Sobreleva apontar que, a propósito da menção de Giddens à sociedade, seria de bom alvitre a conceber na conformação prevista por Taylor 
(2000, p. 236), a saber, reconhecendo que "os povos têm uma identidade, propósitos e mesmo uma vontade, fora de qualquer estrutura política. Em nome dessa identidade, seguindo essa vontade, eles têm o direito de fazer e desfazer estruturas". E, inserto nessas estruturas, por óbvio, se encontra o ordenamento de não-Direito (que, em última análise, é Direito). Ademais, sendo possível que as regulações privadas ou técnico-financeiras façam as vezes do Direito, isso não se dá em oposição ou suplantação a ele, mas em paralelo. E isso é assim porque o Direito não se contenta em defender posições instituídas, mas exerce igualmente funções instituintes, o que supõe a criação de um imaginário de significações sociais-históricas novas e a desconstrução das significações velhas que a elas se opõem. (OST, 2004, p. 19).

Demais disso, aceitar a produção normativa sem a centralidade e o poder do Estado (não-Direito) e compreendê-la, mesmo assim, como Direito (gênero), é condição imperiosa da compreensão do fenômeno jurídico. Não o fazer equivale a ignorar a normatividade de "direitos não oficiais", geralmente, mais vinculativos do que os oriundos de poderes centralizados, como o Estado.

\section{O ESPAÇO DO DIREITO AMBIENTAL GLOBAL}

Tenha-se em mente o cenário de fragmentação jurídica delineado nas seções precedentes: o Direito, enquanto gênero, dividido em duas espécies: Direito e não-Direito. O primeiro, abarca a produção normativa de signo estatal, com ênfase, portanto no poder público, é abstrato, impessoal, cogente, baseado na soberania do território e gerador de normas que ostentam, grosso modo, efeitos ex nunc e incidem às situações fáticas através de subsunção. O segundo, é forjado e congrega a produção normativa oriunda da iniciativa privada, detém, por isso, nítido caráter de poder privado, é concreto, pessoal, cogente ou consensual, excepciona fronteiras e varre territórios e dá azo a normas de efeitos ex tunc, que são aplicadas às relações por meio de expedientes arbitrados (de busca concorde) ou regulados (autorregulação regulada).

Se, no centro desse cenário bifurcado, se manejasse uma bússola, para qual dos dois planos a agulha imantada apontaria como norte? Seguramente, para o do não-Direito. Isso é pernicioso, posto que, no terreno pantanoso das regras extremamente técnicas, especializadas e corporativas, faria falta a segurança do Direito escrito em códigos, constituições ou 
tratados? Talvez; no entanto, há muito a codificação e o dogmatismo não asseguram a fruição dos direitos que prometem, tampouco o Estado representa a higidez de aplicar com autonomia os direitos que enumera.

A verdade é que essa quadra da História e esse pano de fundo de uma transnacionalidade econômica quase libertina exigem, mormente no que se refere com o Direito Ambiental, um parâmetro; e importa que ele seja de proteção e contestação. Já se descobriu que o cenário de Direito não dá conta dessa empresa e, no outro polo, o não-Direito, em seu próprio arbítrio, encaminhar-se-á a uma autorregulação.

Para que se tenha a noção da importância representada pela estrutura transnacional globalizada, Gatto (2011, p. 3) indica que, em 2011, existiam mais de 82.000 empresas transnacionais e 810.000 subsidiárias, as quais desenvolviam praticamente todos os ramos de atividade existentes e tinham sucursais em todo o mundo. Em considerando que esse número tenha aumentado em cinco anos e que a ONU (2016) reconhece apenas 193 Estados, a presença dessa estrutura na vida das, aproximadamente, sete bilhões de pessoas que habitam o orbe terrestre é, quantitativamente, significativa. Ainda nessa temática, Stiglitz (2007, p. 303) dá conta de que "em 2004, as receitas da General Motors foram de 191,4 bilhões de dólares, quantia maior do que o PIB de quase 150 países. No ano fiscal de 2005, o Wal-Mart faturou 285,2 bilhões de dólares, mais que o PIB total da África subsaariana".

Relegar, portanto, a situação a um voluntarismo ético das forças de mercado equivaleria a laborar num equívoco rotundo e pueril, lapso que é comprovado por situações como a ruptura da barragem de rejeitos da Mineradora Samarco, em Mariana, Minas Gerais - possivelmente o maior desastre ambiental verificado no Brasil. É, pois, precisamente nesse ponto nevrálgico que têm assento a emergência de um Direito Ambiental que também se desvele global, transnacional.

Assim é que se poderia supor do despontar de um sistema de normas nacionais e regionais de proteção ao Meio Ambiente em níveis globais, primordialmente de aplicação extraterritorial ${ }^{6}$, possivelmente

\footnotetext{
6 A aplicação extraterritorial de normas protetivas não é novidade, mormente em se tratando de salvaguarda aos Direitos Humanos - e nunca se deve esquecer que o direito ao Meio Ambiente sadio e equilibrado se constitui em direito humano dos mais básicos. "[...] 15 campesinos de Myanmar, valendo-se da condição de anonimato por questões de segurança, promoveram uma lide contra a UNOCAL - Union Oil Company of California (mais tarde incorporada pela Chevron), perante a Corte Federal de Apelação da Califórnia, com fundamento no Alien Torts Claims Act, argumentando que a companhia petrolífera se valia de soldados e milícias para proteção de suas instalações, violando Direitos Humanos, cometendo assassinatos e estupros indistintamente, bem como, utilização de mão de obra escrava. Em matéria de defesa, a UNOCAL aduziu a impossibilidade jurídica do pedido, sob o
} 
representado por algumas diretivas e regulamentos do Parlamento e do Conselho Europeu, tal como a Diretiva 2001/18/CE, que intenta regular e emprestar maiores eficiência e transparência ao processo de concessão de autorizações para a libertação deliberada e a colocação no mercado de organismos geneticamente modificados. Igual modo, a Diretiva 2009/28/ CE disciplina a promoção da utilização de energia proveniente de fontes renováveis.

Além de apresentar normas com efeitos extraterritoriais, o direito europeu apresenta uma abertura à participação de atores não estatais na elaboração e implementação da legislação ambiental. De maneira ilustrativa, por meio de um procedimento de acreditação, são aceitos e reconhecidos esquemas voluntários de certificação privada como meio de comprovação da implementação dos «critérios de sustentabilidade» indispensáveis para a comercialização de biocombustíveis no mercado europeu, de modo que a forma de controle da qualidade sustentável dos biocombustíveis utilizados para alcançar a promoção de energia renovável no setor de transportes constitui uma manifestação prática do direito transnacional. (ANDRADE, 2013, p. 22).

A própria Organização das Nações Unidas já aprovou, em 1983, a Carta da Terra, que preconiza a necessidade de reconhecer a Natureza enquanto "ser", não como mero objeto de utilidade para os seres humanos, temática em que o continente sul-americano é pródigo em exemplos, muitos dos quais de índole constitucional. O artigo 71 da Constituição do Equador estabelece que a Natureza possui direito à existência, manutenção e regeneração de seus ciclos vitais (processos ecológicos essenciais), garantia que pode ser advogada por qualquer pessoa, comunidade ou povoado. Igual modo, o artigo 34 da Constituição da Bolívia também garante ampla proteção jurídica à Natureza, admitindo que qualquer pessoa individual ou coletiva possa defender os direitos de um rio ou uma bacia hidrográfica, por exemplo, perante o Poder Judiciário.

Todavia, sem prejuízo às fontes normativas examinadas, que lançam incidência sobre o Direito Global, há que se guardar atenção especial aos expedientes de soft law e autorregulação ${ }^{7}$, que cada vez mais

argumento de vedação à extraterritorialidade da norma e, no mérito, que tais atos eram de responsabilidade do Estado de Myanmar e das empresas terceirizadas. Na decisão, a Corte Federal de Apelação da Califórnia concluiu que a UNOCAL sabia e/ou deveria saber dos atentados aos Direitos Humanos, por ação dos seus agentes ou das empresas contratadas, devendo, portanto, promover a reparação dos danos. Diante deste cenário, em 2005, a UNOCAL realizou o cumprimento da sentença". (STAFFEN, 2015, p. 93-94).

7 Consistente em: (1) uma forma de regulação, não ausência desta - a autorregulação seria uma es- 
avançam para novos territórios, novos poderes, novas instituições e novos direitos. Na lição de Pardo (2005, p. 10), o diagnóstico da existência dos mencionados expedientes precisa ser analisado sobre o plano da transparência e do debate público, afastando o "autismo" instalado que objetiva negar sua existência a averiguar seus desdobramentos.

\subsection{Soft law e autorregulação}

No que tange ao aspecto conceitual, dar uma definição unitária e exaustiva de soft law, especificamente, não é uma das tarefas mais fáceis, considerando a multiplicidade de fenômenos em que é possível enquadrar esse conceito operacional. Em uma acepção lato sensu, torna-se possível afirmar que o termo em apreciação se refere a todos aqueles fenômenos de regulação e autorregulação diverso dos tradicionais instrumentos normativos provenientes de um processo deliberativo formal de produção legislativa conduzindo perante um poder investido dessa função e, cuja característica essencial é dada pelo fato de ser desprovida de eficácia vinculante direta.

Caudatários dessa consideração, surgem signos de resistência comumente associados à soft law, notadamente acerca de seu conceito e da aparentemente antitética conjugação de seus termos (soft e law). É dizer, a expressão soft seria incapaz de ser conciliada com a ideia de rigidez e dureza vinculante típica da lei. Nesse sentido, a soft law seria, em outra medida, não uma fonte do Direito, mas um paliativo para as vaguezas do Direito Internacional. Ocorre que a soft law, assim como a autorregulação, não se restringe aos limites do Direito Internacional, nem se presta como mero mecanismo integrativo do Direito. O fenômeno da globalização dos ordenamentos jurídicos e o advento de um Direito Global introduziu a soft law como fonte normativa em um complexo e fluído regime jurídico global.

pécie do gênero regulação -; (2) uma forma de regulação coletiva, pois não existe autorregulação individual - envolve uma organização coletiva que estabelece e impõe aos seus membros certas regras e certa disciplina -, e, (3) uma forma de regulação não estatal. (MOREIRA, 1997, p. 22). Podem ser citados como exemplos de autorregulação: (1) ordens profissionais, como a Ordem dos Advogados do Brasil: considerada autorregulação pública, visto que exercida por organismos de representação profissionais dotados de estatuto jurídico público. Sendo legalmente estabelecida, a autorregulação desses organismos lhes empresta poderes típicos de autoridade pública; (2) a Associação Brasileira de Normas Técnicas (ABNT): autorregulação privada oficialmente reconhecida: entidade privada sem fins lucrativos criada em 1940 e reconhecida, pela Resolução número 7 do Conselho Nacional de Metrologia, Normalização e Qualidade Industrial como "único foro nacional de normalização"; (3) Níveis de Governança Corporativa da Bolsa de Valores de São Paulo: segmento de listagem diferenciada de ações cujas companhias, voluntariamente, aquiescem em acrescer às obrigações legais outras decorrentes do risco da atividade. 
A autorregulação, define Dernaculleta i Gardella (2005, p. 24), noutro plano, se apresenta como manifestação da capacidade que possuem os sujeitos privados de aprovar e garantir a satisfação de normas de comportamento que devem respeitar no exercício das atividades a que estão associados.

Em relação ao aspecto teleológico, tanto a soft law quanto a autorregulação, no cenário do Direito Global, assumem uma tríplice funcionalidade. Primeiro como mecanismos de normatização de condutas a partir de atos específicos, dinâmicos e atentos à complexidade do global e suas interfaces com o local, nacional, internacional e supranacional. Segundo, como expedientes para especificação de disposições de normas provenientes dos poderes estatais, com o objetivo de detalhamento e aprimoramento da generalidade e abstração da hard law. Terceiro, como práticas comparativas, segundo a qual, o propósito de sua adoção está na orientação dos comportamentos jurídicos, políticos, sociais e institucionais para escolha de normas dotadas de maior efetividade, eficácia e eficiência.

Em igual medida, advertem Paixão e Bertoldi (2012), há que se considerar que o incremento no uso de expedientes de soft law e autorregulação se deve, principalmente ao contexto desvelado pela globalização associado ao diagnóstico de paquidermia dos entes estatais em enfrentarem problemas concretos e emergentes. O uso comum de soft law e autorregulação para questões de meio ambiente, saúde, agricultura, tecnologia, comunicações, seguridade, engenharia, relações comerciais e negocial se instala proporcionalmente pelo fato dos Estados e dos entes de Direito Internacional evitarem tratar direta e efetivamente desses assuntos, seja por protecionismo, seja por nacionalismo, seja por sua própria debilidade institucional.

O desenvolvimento das técnicas e fontes de produção jurídica que transcendem aos métodos e procedimentos tradicionais reconhecidos, correspondem a uma exigência de ratio jurídica em grau de prevalência sobre lógicas produtivas individuais que aparecem em alguns setores da vida social introduzidos em regras de Direito, determinando e orientando comportamentos de sujeitos não apenas privados, mas também públicos.

A soft law, materializa um complexo insumo de instrumentos racional e voluntariamente idealizados a partir de vários atores públicos e privados, nacionais, internacionais, supranacionais, transnacionais e globais, governamentais ou não-governamentais, vinculados a múltiplos ordenamentos jurídicos que, com o desiderato de obterem um resultado 
mais preciso e efetivo, resolvem gerir os fluxos dinâmicos da sociedade global, plasmando e estruturando institucionalmente suas bases sobre os preceitos da soft law.

Diverso do que atestou Ferrarese (2000), a soft law não se trata apenas de uma "giuridicità camaleontica" a servir unicamente ao mercado. A soft law manifesta a vontade de fazer imperar sobre as forças da globalização e da mobilidade de bens, serviços, instituições e pessoas o Direito sobre, inclusive, a Economia. Ela é a expressão mais dúctil, menos rígida, porém cogente, que graças à sua caracterização soft consegue se inserir com maior velocidade e efetividade em espaços marcados pela estratificação dos poderes e mobilidade reduzida. Em síntese, os preceitos da soft law asseguram uma nova garantia de responsive law.

Em linhas gerais, a soft law se apresenta e é apresentada sobre pilares que podem ser caracterizados como apenas um conceito, que se opõe à normatividade vinculante da hard law, ou como um núcleo normativo que guarda em si uma tipologia específica de atos com procedência jurídica própria, ou como uma técnica normativa, assim representada na sua peculiar sistematização para produção de seus cânones, ou, por último, como uma miscelânea de cada atributo.

Nesse sentido, há um resultado perene imediato que sinaliza a perigosa propensão ao estabelecimento de uma definição rígida ao fenômeno da soft law, enquanto função e instituição. Afinal, os conceitos normativo, técnico ou híbrido associado à soft law não estão completamente equivocados. Por sua vez, tal abertura do instituto da soft law representa a crescente e progressiva importância que a mesma assume na Ciência Jurídica e no trato das relações intersubjetivas e institucionais.

Em que pese o respeito ao grupo que prefere analisar a soft law como apenas um atributo conceitual, parece ser contraproducente, nos dias atuais, negar a influência que expedientes de soft law produzem no comportamento dos sujeitos jurídicos e seus respectivos efeitos, também jurídicos ${ }^{8}$. Apenas como ilustração, há que se mencionar o papel cada vez

8 Nesse sentido, em relação à autorregulação merece transcrição: "La que, en términos generales, podríamos llamar la normalización privada, ha dejado de ser una actividad espontánea, desarticulada y parcial para convertirse en un fenómeno sistémico. Hace treinta años, la jurisprudencia alemana, desconcertada ante el avance de las normas técnicas de su potente industria, alumbró una fórmula feliz para catalogarlas: eran meros dictámenes técnicos anticipados, sin valor normativo vinculante. Todavía se podía mantener eso entonces, porque la actividad de normalización técnica estaba todavía muy diversificada - asociaciones profesionales, centros de investigación, grandes empresas y otros sujetos que las elaboraban - y era posible, en principio, conseguir un "contradictamen", otra norma técnica que pudiera aplicarse al caso. Hoy el proceso de normalización industrial se ha sistematizado, se ha cerrado, y el sistema tiende a ofrecer una única solución, válida como mínimo para toda Europa, 
mais "vinculante" que Regulamentos, Códigos de Conduta, Protocolos, Certificados Técnicos, Selos e Diretivas exaradas por atores supranacionais, transnacionais ou globais, exercem sobre os poderes e instituições públicas nacionais ${ }^{9}$. Portanto, não se trata apenas de normas de cunho privado e de aplicação facultativa, mas pelo contrário, de espraiamento de sua cogência para além do atributo institucional-soberano nacional.

A partir desse cenário, o que se analisa é certa polarização sobre o mérito da soft law. Por um lado, os entusiastas ${ }^{10}$ da soft law e da autorregulação consideram que a abordagem da soft law oferece muitas vantagens: ação oportuna quando os governos estão paralisados; iniciativas de baixo para cima que trazem legitimidade, expertise e outros recursos adicionais para a elaboração e aplicação de normas e padrões e; um meio eficaz para a participação direta da sociedade civil na governança global. Por outro lado, críticos radicais ${ }^{11}$ argumentam que a soft law é suave com atores de mercado agressivos e oportunistas, que sob o escudo da legalidade abrandada conseguem transferir custos para a sociedade e difícil para atores fracos.

Em resposta parcial a essa investida, Dernaculleta i Gardella (2005, p. 26-28) defende uma técnica complementar e nova de autorregulação, cuja fundamentação reside no estabelecimento de instrumentos de regulação pública da autorregulação, capaz de exercer a minimização dos riscos, otimizando os níveis de proteção mediante: atividade pública de fomento da autorregulação, ou seja, políticas de empoderamento que envolvam a coletividade; atribuição de efeitos públicos para os instrumentos de autorregulação, de modo que todos possam, inclusive o Estado, depositar confiança nos atos autorregulados e; regulação do contexto de autorregulação, tornando-o transparente e democrático.

Assim, para os entusiastas, a soft law é suscetível de produzir uma governança global mais eficaz, promovendo a abertura econômica, a valorização dos ideais de direitos humanos, de o aprimoramento ambiental e a coesão social, mas para os críticos é mais um padrão de recepção de categorias americanas mal adequadas o tecido do direito continental

con lo que la teoría del dictamen se desvanece y nos enfrentamos a la imposición fáctica de la solución única." (PARDO, 2005, p. 16).

9 A título ilustrativo: Diretiva da União Europeia sobre Venda à Distância (07/1997), especificamente art. 11.4: "Member States may provide for voluntary supervision by self-regulatory bodies of compliance with the provisions of this Directive and recourse to such bodies for the settlement of disputes to be added to the means which Member States must provide to ensure compliance with the provisions of this Directive."

10 Como Kirton e Trebilcock (2004, p. 05).

11 Como Di Robillant (2006, p. 508-509). 
europeu. (ZERILLI, 2010, p. 10).

Na mesma toada, os expedientes de soft law e autorregulação não podem ser imputados como responsáveis pelo fenecimento da hegemonia estatal-nacional. A implementação desses mecanismos normativos visa prioritariamente ocupar vácuos de regulação não exercida ou exercida com debilidade pelo Estado e seus organismos. Tal qual pontou Grossi (2017), sobre a ordem jurídica medieval e, dada suas similitudes com o paradigma global atual, a experiência jurídica contemporânea traz à lume um conjunto de valores fortemente incisivos e largamente difusos que criam uma particular mentalidade jurídica, oferecendo escolhas jurídicas precisas para os grandes problemas da vida social. Portanto, os argumentos que posicionam os instrumentos de soft law e autorregulação como instrumentos de privatização das funções estatais legiferantes restam comprometidos pela natureza de suplementação e especificação normativa.

Em complemento, em conclusão imediata o que se observa é a emergência de mecanismos de compulsoriedade das condutas em relação à soft law que não se resumem apenas ao que outrora foi definido como institutos de aplicabilidade facultativa interna corporis. Há inerentemente à soft law o exercício de obrigatoriedade de suas prescrições, porém em medida distinta ao que se atribui para as normas derivadas do poder dos Estados. Mesmo assim, vale reiterar a condição de cogência que ambas possuem. Ademais, já alertava Villary (1960, p. 77), uma norma não é jurídica porque ela é capaz de impor sanção, ela sanciona justamente por ser jurídica.

Nesse sentido, superada a análise da soft law a partir da decomposição das características inglesas da hard law (no compreender de Bernardi (2009, p. 02-04) norma produzida através de procedimento pré-determinado baixo a autoridade de um ente e/ou de uma instituição que produz uma norma dotada de eficácia vinculante no confronto com os destinatários), o que se vislumbra na dinâmica da globalização jurídica é a expansão da soft law enquanto prática jurídica justamente pela condição tendencialmente livre de vínculos estatais e por estar mais próxima das matrizes transnacionais e globais, dos entes e dos poderes desterritorializados, podendo, desse modo, ofertar respostas mais rápidas, precisas e efetivas às demandas globais, ainda que com circunscrição local/ regional.

A soft law se contrapõe aos tradicionais instrumentos de normatização (leis, regulamentos, tratados, etc), consideradas como hard 
law, segundo o procedimento dos sujeitos que estão responsáveis por produzir tais instrumentos (parlamentos, governos etc), os quais entregam um produto que impede, salvo exceção legal, a escusa em sua satisfação. Surge desse preceito a condição vinculante da hard law no confronto com os destinatários. Portanto, a garantia de efetividade da hard law está na presunção de submissão do destinatário para com a norma.

Em que pese a suposta falta de eficácia vinculante direta, a garantia de observância das normas de soft law repousa sobre o fato que tais normas emanam dos respectivos destinatários (autorregulação) ou da interferência dos sujeitos que a emanam através de sua força persuasiva. Também podem ser caracterizadas como normas de soft law os preceitos normativos que se limitam a fixar princípios e diretrizes de características gerais, deixando aos destinatários espaços de maior autonomia para a escolha dos modos de atuação específica da norma (soft law). Neste caso, vale mencionar a experiência da União Europeia, a partir do art. $5, \S 4^{\circ}$, do seu tratado constitutivo.

Ademais, retomando o debate sobre a condição vinculante de normas de hard law vs. soft law, urge ressaltar que ao se negar a juridicidade de normas desprovidas de sanção, corre-se o risco de se negar a juridicidade de normas insculpidas no texto constitucional, na legislação infraconstitucional e no próprio Direito Internacional. A ciência jurídica, admoestam Paixão e Bernardi (2012), especialmente não nega a juridicidade dos costumes, da analogia, da equidade e dos princípios gerais do direito como fontes do próprio Direito.

Ainda no que tange ao argumento da coerção das normas, importa dar relevo ao fato da associação dos atributos da hard law aos preceitos do Estado Moderno, sendo este o detentor exclusivo do uso da força necessária para regular as condutas de seus sujeitos. Desse modo, a máxima de eficácia imediata vinculante das normas ganhou pujança com a simbiose entre Direito, poder e força, ocorrida no núcleo dos Estados nacionais surgidos após os Tratados de Paz da Westphalia.

Evidente que a cogência surge como elemento importante do fenômeno jurídico, correlacionada com a atividade da norma jurídica. Contudo, se o problema do binômio força e Direito, emerge do uso da força como ponto de distinção, provavelmente não haverá solução jurídica. Por outro lado, se a força é o objeto imediato de apenas algumas normas dos ordenamentos jurídicos, restaria prejudicada a própria tese de ordenamentos jurídicos, pois como tal se constituem num corpo coeso e não em pontos 
isolados de normatização. Portanto, conclui Mostacci (2008, p. 22), a cogência resulta em elemento necessário e nuclear dos ordenamentos e como tal, se manifesta em todas as normas desses.

Nesse sentido, a relação entre Direito e força, principalmente sua utilização para refutar a natureza normativa e de fonte do Direito da soft law, resta prejudicada pelos argumentos expostos. O problema não está na graduação de rigidez e autoridade do Direito, mas no novo formato de imposição da cogência pela autoridade responsável, que deixou de ser absolutamente soberana, territorializada, burocrática, para ganhar atributos de fluidez, interconectividade, especificidade e responsividade.

Em relação à autorregulação, impera a condição de desnecessidade de habilitação desde cima. Em linhas gerais, a autorregulação, a partir de uma observação sociológica tem em seu núcleo atributos de autopoiese, na visão sistêmica de Luhmann (1990).

Desse modo, seu impulso provém de movimentos nas bases que ativam compromissos de autorregulação normativa e fórmulas de resolução de conflitos. Quem quebra a inércia para fins de parametrização de condutas através de autorregulação são profissionais, técnicos, investidores, médicos, comunicadores, como outrora, foram os mercadores que construíram as bases das legislações comerciais. Além de criarem normas, definem de maneira efetiva e eficaz modelos de resolução de controvérsias, sem nenhuma delegação ou encargo estatal. Diante disso, Pardo (2005, p. 15) atesta que, tanto pela sua validade, quanto por sua efetividade, tem a autorregulação atraído a atenção dos entes estatais para incorporação de seus conteúdos.

Nesse sentido, há que se destacar, no âmbito da soft law, ainda que rotulado (equivocadamente) como mero mecanismo de adesão voluntária, a distinção que deve ser feita sobre suas características jurídicas e aquelas que assumem natureza política e/ou social. No primeiro caso, as normas decorrentes de soft law fixam instrumentos de cogência, com o desiderato de garantir a observância pelas partes destinatárias dos preceitos formais e substanciais estabelecidos nela. Noutro lado, deriva da sua cogência o aspecto pedagógico de reprodução das condutas dotadas de tratamento normativo na coletividade, instituindo, de modo consuetudinário, em fonte de regulação e aditamento não mais inter partes, reestabelecendo preceitos ancestrais do rule of law.

Consequentemente, o que se desprende do argumento acima sublinhado é o aparecimento de um duplo relevo jurídico da soft law que 
se funde no aspecto interno e no aspecto externo da juridicidade da norma, de modo que ambos, possuem condições de influenciar o desenvolvimento de mecanismos normativos estatais e não-estatais. Com isso, há que se notar o crescente número de leis e atos legislativos ou executivos estatais que incorporam preceitos normativos provenientes de soft law ou autorregulação ${ }^{12}$ (nesse caso, autorregulação regulada, no dizer de Dernaculleta i Gardella (2005, p. 388 e ss.).

Os atos normativos de soft law e autorregulação, adverte Mostacci (2008, p. 39), sob o ponto de vista da Política Jurídica, resultam em imprescindíveis subsídios, ao efeito de potencializar a dinâmica e a circulação de seus próprios atos e da sua interação como instrumentos ordinariamente taxados como hard law. Tal mimetismo supera a divergência sobre o aspecto da cogência de ambos os mecanismos para capacitar os modelos jurídicos em tempos da globalização (inclusive jurídica) para respostas mais eficazes e efetivas.

Em complemento, a eficácia normativa da soft law e da autorregulação impõe a satisfação de dois outros princípios fundantes, compulsoriamente, a saber: a presunção de licitude, segundo a qual, as condutas dos sujeitos regulados devem ser consideradas juridicamente válidas, salvo desconsideração da presunção e; a presunção de boa-fé, pela qual se opera sobre o plano formal e substancial, assegurando a satisfação da convenção genuína e o respeito interno e externo em relação à norma.

É bem verdade que a condição de eficácia e de efetividade nas normas de soft law e de autorregulação necessitam de uma filtragem no que tange à legitimidade do poder utilizado para a normatização de dadas situações fáticas. Não se ignora a probabilidade de existência de normas de soft law ou autorregulação eficazes, mas, porém, "ilegais", algo que ocorre também na hard law. Entretanto, para minimizar tais episódios, há que existir nos órgãos responsáveis por sua edição instrumentos preventivos

12 Apenas para ilustrar, a partir da realidade brasileira é possível apontar como exemplos diretos, selecionados aleatoriamente, dessa otimização da atividade legiferante com o acoplamento de expedientes de soft law e autorregulação nas normas estatais nos últimos 15 anos: Emenda Constitucional 45/2004 (Reforma do Poder Judiciário), inclusão de recomendações do Documento Técnico 319/1996 produzido pelo Banco Mundial; Decreto 6.583/2008 (Acordo Ortográfico da Língua Portuguesa), internalização de acordo celebrado por ente transnacional para padronização da ortografia lusófona; Lei Complementar 131/2009 (Lei da Transparência), influência direta do preceitos da ONG Transparência Internacional; Lei 12.663/2012 (Lei Geral da Copa do Mundo de Futebol), redação conforme convênio celebrado com a FIFA; Lei 12.965/2014 (Marco Civil da Internet), respeito aos preceitos instituídos pela ICANN; Lei 13.260/2016 (Lei Antiterrorismo), influência direta do GAFI, mediante memorandos, para controle de movimentações financeiras para suporte a grupos terroristas; Lei 13.322/2016 (Lei Antidopagem), adota prescrições da WADA para fins de controle sobre o uso de substâncias proibidas para prática desportiva. 
e repressivos de controle, isto é, nas palavras de Dernaculleta i Gardella (2005, p. 296), a responsabilidade pelo autocontrole.

Confirmando a hipótese especulada por Snyder (1993, p. 80), a soft law vem adentrando no núcleo de vários ordenamentos jurídicos nacionais. Se insere sob a forma de convênios para investimentos, formação de blocos supranacionais, desenvolvimento e compartilhamento de novas tecnologias, regulação de novos bens e serviços, adequação de institutos em vigência. Em suma, o movimento de mobilização transnacional e global do Direito, encontrou na soft law e na autorregulação fontes poderosas para constituição, mutação, flexibilização, complementação e articulação de normas jurídicas antes dependentes do Estado.

Nesse sentido, a existência de tais ligações entre $o$ ato normativo proveniente de fontes típicas de lei e a soft law (assim como a autorregulação) tem um duplo significado. Em primeiro lugar, a partir de um ponto de vista formal, atrai o instrumento em questão dentro do sistema regulamentar global, com o efeito de torná-lo parte integrante do ordenamento nacional. Desta forma, é a mesma lei positiva que determina a legalidade do instrumento de soft law. Noutro lado, a ligação destes atos com uma determinada ordem jurídica propícia uma relação dialética com a sua aplicação judicial. Estas ferramentas têm a capacidade de definir regras, em cada ordenamento jurídico, desfrutando do mesmo caráter geral como as da hard law, apesar das diferenças relativas. Na verdade - pondera Mostacci (2008, p. 25-27) -, eles foram capazes de intervir no sistema legal, inovando as regras.

Assim, aos atores interessados nos fenômenos transnacionais e globais, com efeito jurídico e edificantes de novos modelos normativos, a pujança da soft law e da autorregulação é clarividente, com características próprias de normatividade, validade, cogência, eficácia e efetividade. A soft law e a autorregulação ocupam espaços normativos relevantes e impossíveis de serem deixados vazios. Para ilustrar essa percepção, urge destacar o movimento do Governo Estadunidense, sob a gestão de Donald Trump, que, ao resolver denunciar com o Acordo de Paris sobre Mudanças Climáticas (COP 21), de imediato alimentou múltiplas manifestações setorizadas, públicas e privadas que, de forma peremptória, ratificaram sua disposição em se manter fiel aos preceitos dos padrões definidos pela Cúpula. A saída de um ente estatal, fez com que atores locais, transnacionais e globais invocassem para si a responsabilidade de normatização para obtenção dos mesmos objetivos. 
Como consequência, a soft law e a autorregulação assumem condição normal de serem associadas como fontes do Direito. No campo do Direito Global, essa condição é perene. Confluem os mecanismos de soft law e de autorregulação como instrumentos utilizados a introduzirem, modificarem e/ou inovarem nos ordenamentos e regimes jurídicos, prescrevendo valorações de natureza substancial sobre os conteúdos preceituados. (ZAGREBELSKY, 1984).

No dizer de Bin (2009, p. 35), há que se considerar que fontes do Direito não são apenas os elementos prescritivos que produzem normas, mas, conforme adverte Bin, fontes do Direito também podem ser elencadas as ações que inovam com o próprio ordenamento, de tal sorte que, negar tal condição importa não apenas em um problema teórico, mas com relevantes consequências fáticas.

Ocorre que a opção deliberada pela negação ou pela ignorância dos mecanismos de soft law e autorregulação transitam de encontro com a dimensão da eficácia das normas jurídicas, estas entendidas como a capacidade da norma de prever em abstrato e, como necessário, que um fato alcance determinada consequência restando ao momento futuro sua efetividade em concreto. O volume de normas produzidas dentro das margens dos Estados e do Direito Internacional, atualmente, resta superado pelas redes transnacionais e globais, aponta Teubner (2012, p. 153).

Noutro sentido, a inserção de instrumentos de soft law no sistema de fontes do Direito tem estimulado a avaliação sobre a função interna que exerce nos ordenamentos. Sobre esse ponto, é possível observar como duas temáticas principais colocam em dificuldades os princípios regulatórios clássicos, concebidos no seio do Estado Moderno, isto é, o comando da função autoritária e a imposição de sanções por parte dos poderes soberanos e que encontram na lei (hard law) sua própria e principal aplicação ${ }^{13}$. Conforme adverte Catania (2010, p. 102), a normatividade é a pretensão de obediência e de reconhecimento que influencia no ato através da sua efetividade, portanto, não carece compulsoriamente dos vínculos estatais para tal caracterização.

Acontece que, sistematicamente, esse legiscentrismo hegemônico do Estado se encontra debilitado e corroído. As conexões globais entre mercados, instituições, mercadorias, serviços e pessoas acabaram por

13 "Sul punto è possibile osservare come due tematiche principal mettano in difficoltà il modello regolatorio classico, costituito nel comando di stampo autoritativo e corredato di sanzione da parte del potere sovrano; modello che trova nella legge la propria principale applicazione. Dette difficoltà, nel momento in cui richiedono strumenti regolatori innovativi, costituiscono la ragion d'essere della progressiva diffusione conosciuta dagli strumenti di soft law." (MOSTACCI, 2008, p. 28). 
destacar a insuficiência de parte considerável dos atributos do Estado, tal qual consignado alhures, seja pela peculiaridade das demandas, pela preocupação com externalidades, pela competência institucional ou pelo fator "tempo do Direito". Paralelamente, as pretensões de cunho global que se apresentam para tratamento jurídico guardam exigências de ordem cada vez mais específica e ad-hoc, sobre as quais os entes modernos se mostram impotentes.

Os instrumentos de soft law e autorregulação, sobre esse aspecto, se apresentam particularmente receptivos aos novos anseios decorrentes dos fluxos da globalização. Sua ductibilidade, associada com efeitos vinculantes, bem como, pela cogência dada por efeitos indiretos, assegura aos agentes e destinatários da norma grau maior de autonomia e regulação efetiva, sem impor uma ordem de exclusão sumária para com os preceitos da hard law.

Pelo cenário exposto, emerge uma mutação dos modelos de regulação modernos, não mais concentrados sob a norma rígida que se impõem para todos, genericamente, mas atento à exigência de fazer da norma um instrumento capaz de adaptar-se a dinâmica social, política, econômica, institucional e jurídica em constante evolução.

Embora a força da lei (Direito) esteja tradicionalmente ligada ao seu poder de obrigar (por meio de sanções formais), Zerilli (2010, p. 7) sublinha que a força da lei global (transnacional ou não-Direito) residiria na sua capacidade de se adaptar a diferentes circunstâncias, isto é, à sua maleabilidade e ductibilidade. Nesta perspectiva, é prático referir-se à soft law como uma tecnologia específica de produção de lei (global), não no sentido de sua capacidade de se tornar "lei dura" no futuro, como argumentariam vários estudiosos da lei, mas, em vez disso, como uma maneira específica de reforçar a conformidade usando meios diferentes, geralmente autorregulatórios. Isso é consistente com a lógica dominante da governança neoliberal, que, atualmente, tem discutido a "cultura da auditoria", como lembra Shore (2008, p. 284).

Não por acaso, o que se vislumbra é a concretização da derrocada do conceito uniforme de lei/norma para o estabelecimento de modelos complexos de pluralismo jurídico, verdadeiro pluralismo legal global. Em virtude de tal estado d'arte, a soft law e a autorregulação ganham significação jurídica de relevo como fontes normativas. Ambas superam a estratificação no núcleo do Direito Global para entrarem na pauta de juristas que possuem como objeto de estudo o Direito Nacional ou o Direito 
Internacional, pois seus efeitos se aderem e/ou alteram de alguma forma o fenômeno jurídico local, regional, nacional, internacional, supranacional, transnacional e global.

No que pertine diretamente com o Direito Ambiental Global, esse pano de fundo é animador, como se pode denotar, por exemplo, da norma ISO 14.000, de caráter voluntário e amplamente difundida no cenário transnacional, editada pela International Organization for Standardization, maior organização não-governamental desenvolvedora de normas internacionais voluntárias.

Para além disso, construções híbridas que combinam políticas públicas e estratégias corporativas privadas também se desvelam indutoras de relações policêntricas que desenvolvem e permeiam o Direito Ambiental Global.

Nesse norte, o case brasileiro envolvendo o cultivo da palma na Amazônia é emblemático. Relatada em estudo de caso por Veiga e Rodrigues (2016, p. 01-22), a expertise, a uma, realça a influência da arena transnacional no âmbito das relações internacionais, e, a duas, sublinha a influência do setor privado nas políticas públicas em âmbito doméstico (nacional), com base na estratégia corporativa de uma empresa na Câmara Setorial da Palma de Óleo, criada sob a supervisão do Ministério da Agricultura, Pecuária e Abastecimento.

Existe uma sinergia entre a estratégia corporativa da empresa brasileira produtora de óleo de palma e a política pública que a incentiva. A ação coletiva em torno da palma é provida pelo governo e por atores não estatais que criaram o espaço de barganha e interlocução - a arena de negociação denominada Câmara Setorial, criada em 2010 no Ministério da Agricultura, Pecuária e Abastecimento (MAPA). Na perspectiva governamental, a política pública para a palma é um incentivo à produção sustentável, baseada na regulação ambiental (e na proibição ao desmatamento) e no desenvolvimento social, com a inclusão de pequenos produtores da agricultura familiar. As agências governamentais - Empresa Brasileira de Pesquisa Agropecuária (Embrapa) e Instituto Nacional de Pesquisas Espaciais (Inpe) - disponibilizaram conhecimento científico no qual a política pública foi ancorada. Na perspectiva empresarial, a atuação da(s) empresa(s) na Câmara Setorial foi essencial para o estabelecimento de parâmetros socioambientais mínimos para a produção e a comercialização negociados com as agências governamentais e demais partes interessadas. (VEIGA e RODRIGUES, 2016, p. 02). 
$\mathrm{O}$ aspecto relevante dessa cooperação repousa, indene de dúvida, na regulação do cultivo da planta em florestas nativas brasileiras, a despeito do argumento (EURACTIV, 2017) global comumente manejado, no sentido de que a produção da palma ocasiona desmatamento, déficit de biodiversidade e conversão de áreas pantanosas em de plantio. Foi justamente a partir dessa premissa que a Organização não-Governamental WWF, juntamente com empresas transnacionais, iniciou as discussões para a estipulação e adesão a padrões mínimos.

Tem-se, na lavra de Büthe e Mattli (2011), a constituição de arenas transnacionais por meio de processos decisórios que envolvem a criação de regras e normas e a implementação de ajustes que não se submetem ao controle e à influência do Estado e das organizações internacionais, em nítida produção soft law. No caso citado, o espaço transnacional é definido por um processo que Hale e Held (2011, p. 01-36) designaram de multistakeholder, com estímulo de mercado para o enforcement de regras adotadas e a verificação da adesão a elas (compliance), o que se dá, segundo Perosa (2012), por meio de auditoria e esquemas de certificação socioambiental.

As chamadas iniciativas multistakeholder se constituem em espaços de negociação arquitetados para organizar a produção e a comercialização entre as partes interessadas dos principais países produtores e consumidores (HALE e HELD, 2011, p. 15) - Better Cotton Initiative para o algodão, Bonsucro para o açúcar e o etanol, Round Table on Responsible Soy (RTRS) para a soja e o RSPO para o óleo de palma. Raciocínio semelhante se pode estender às tentativas, patrocinadas pela Câmara Setorial da Cadeia Produtiva da Erva Mate, de qualificar o produto como orgânico perante a União Europeia (Selo Bio).

Diante disso, se verifica manifesta e importante concretização do soft power brasileiro - compreendido na acepção que lhe atribuiu $\mathrm{Nye}^{14}$, de poder de cooptação ou habilidade de moldar o que os outros querem através da atratividade de sua cultura e valores ou ainda da capacidade de propor a agenda -, apto, a um só tempo, a produzir modificações sociais e sustentabilidade.

14 "Soft power is not merely the same as influence. After all, influence can also rest on the hard power of threats or payments. And soft power is more than just persuasion or the ability to move people by argument, though that is an important part of it. It is also the ability to attract, and attraction often leads to acquiescence. Simply put, in behavioral terms soft power is attractive power. In terms of resources, soft-power resources are the assets that produce such attraction". (NYE, 2004, p. 6). 


\section{CONCLUSÃO}

O processo - desencadeado pela globalização econômica e jurídica e pela transnacionalização do fenômeno jurídico - que fragmenta o Direito em espaços de Direito e não-Direito se constitui no pano de fundo que emoldura também o Direito Ambiental Global.

A conformação do Direito enquanto ordenamento jurídico calcado sobre a teoria da norma jurídica (conjunto ou sistema) é herança positivista e que ostenta a nítida pretensão de definição do Direito através da autolegitimação: é Direito aquilo produzido de acordo com regras específicas do próprio sistema, por autoridade reputada competente ou com atribuição e seguindo procedimento rígido de elaboração, arquitetura esta que se alterou de modo signficativo e irrevogável.

O não-Direito, qualificado como a regulação oriunda - por meios coercitivos ou consensuais - de entes sem centralidade política e detenção exclusiva do poder legiferante, grosso modo privados ou sem ligação pública, que normatiza relações concretas e até pessoais de nítido caráter privado, outrora imaginado como mero suprimento de lacuna ou limbo do Direito (regulamentação jurídica oficial, proveniente de um ente político centralizador que detem, de forma exclusiva, o poder legiferante), no momento presente, se produz e dse esenvolve à margem deste último $\mathrm{e}$ de forma autônoma.

Nessa toada, normas de soft law e a autorregulação se soerguem como instrumentos de concretização de produção normativa consensual, técnica e efetiva, cada vez mais avançando para novos territórios, novos poderes, novas instituições e novos direitos. Apresentam, assim, particularmente receptivos aos novos anseios decorrentes dos fluxos da globalização. Sua ductibilidade, associada com efeitos vinculantes, bem como, pela cogência dada por efeitos indiretos, assegura aos agentes e destinatários da norma grau maior de autonomia e regulação efetiva, sem impor uma ordem de exclusão sumária para com os preceitos da hard law.

Pelo cenário exposto, emerge uma mutação dos modelos de regulação modernos, não mais concentrados sob a norma rígida que se impõem para todos, genericamente, mas atento à exigência de fazer da norma um instrumento capaz de adaptar-se a dinâmica social, política, econômica, institucional e jurídica em constante evolução, caracteres que se amoldam à exigência e ao despontar de um Direito Ambiental Global. 


\section{REFERÊNCIAS}

ANDRADE, Priscila Pereira de. A emergência do direito transnacional ambiental. Revista de Direito Internacional, Brasília, v. 13, n. 3, p. 1728, 2013.

ARCHIBUGI, Daniele. The global commonwealth of citizens: toward cosmopolitan democracy. Princeton: Princeton University Press, 2008.

ARNAUD, André-Jean. Governar sem fronteiras: entre globalização e pós-globalização. Rio de Janeiro: Lumen Juris, 2007.

ARNAUD, André-Jean. Prefácio. In: ARNAUD, André-Jean; JUNQUEIRA, Eliane Botelho (Org.). Dicionário da Globalização: Direito - Ciência Política. Rio de Janeiro: Lumen Juris, 2006.

ASSOCIAÇÃO BRASILEIRA DE NORMAS TÉCNICAS. Conheça a ABNT. Disponível em: <http://www.abnt.org.br/abnt/conheca-a-abnt>. Acesso em: 16 out. 2016.

BACKER, Larry Catá. Globalização Econômica e Crise do Estado: Um estudo em quatro perspectivas. Tradução: Carolina Munhoz e Welber Barral. Revista Seqüência, Florianópolis, n. 51, p. 255-276, jan. 2005.

BERNARDI, Alessandro. Soft law e diritto penale: antinomie, convergenze, intersezioni. In: SOMMA, Alessandro. Soft law e hard law nelle società postmoderne. Torino: Giappichelli, 2009.

BECK, Ulrich. O que é globalização? Equívocos do Globalismo: respostas à Globalização. Tradução: André Carone. São Paulo: Paz e Terra, 1999.

BIN, Roberto. Soft law, no law. In: SOMMA, Alessandro. Soft law e hard law nelle società postmoderne. Torino: Giappichelli, 2009.

BOLSA DE VALORES, MERCADORIAS E FUTUROS. Diretrizes de governança corporativa. Disponível em: <http://ri.bmfbovespa. com.br/fck_temp/26_2//Diretrizes_de_Governanca_Corporativa_da BMFBOVESPA.pdf>. Acesso em: 16 out. 2016.

BÜTHE, Tim; MATTLI, Walter. The new global rulers. Princeton: Princeton University Press, 2011. 
CATANIA, Alfonso. Metamorfosi del diritto. Decisione e norma nell'età globale. Roma-Brai: Laterza, 2010.

COTTERRELL, Roger. What is transnational law? Law \& Social Inquiry - Queen Mary University of London, London, n. 2, p. 340-372, 2012.

CRUZ, Paulo Márcio; BODNAR, Zenildo. A transnacionalidade e a emergência do Estado e do Direito transnacionais. In: STELZER, Joana; CRUZ, Paulo Márcio (Org.). Direito e Transnacionalidade. Curitiba: Juruá, 2009.

DERNACULLETA I GARDELLA, Maria Mercè. Autorregulación y derecho público: la autorregulación regulada. Barcelona: Marcial Pons, 2005 .

DI ROBILLANT, Anna. Genealogies of soft law. American Journal of Comparative Law, v. 54, 2006.

EURACTIV. Parliament committee says palm oil biofuels usage should end by 2020. 2017. Disponível em: <https:/www.euractiv.com/section/ agriculture-food/news/parliament-committee-says-palm-oil-biofuelsusage-should-end-by-2020/>. Acesso em: 22 mar. 2017.

GATTO, Alexandra. Multinational enterprises and Human Rights: obligations under EU law and international law. Cheltenham (Reino Unido): Edward Elgar Publishing Limited, 2011.

FERRARESE, Maria Rosaria. Le istituzioni della globalizzazione. Bolonha: Il Mulino, 2000.

GIDDENS, Anthony. As consequências da modernidade. Tradução: Raul Fiker. São Paulo: Editora UNESP, 1991.

GROSSI, Paolo. L'ordine giuridico medievale. Bari-Roma: Laterza, 2017.

GROSSI, Paolo. Mitologias jurídicas da modernidade. 2. ed. rev. e ampl. Tradução: Arno Dal Ri Júnior. Florianópolis: Fundação Boiteux, 2007.

HABERMAS, Jürgen. A constelação pós-nacional. Tradução: Márcio Seligmann-Silva. São Paulo: Littera Mundi, 2001.

HALE, Tom; HELD, David. Editor's introduction: mapping changes in transnational governance. In: HALE, Tom; HELD, David. Handbook of transnational governance. London: Polity Press, 2011. 
INTERNATIONAL ORGANIZATION FOR STANDARDIZATION. About ISO. Disponível em: <http://www.iso.org/iso/home/about.htm>. Acesso em: 13 out. 2016.

INTERNATIONAL ORGANIZATION FOR STANDARDIZATION. ISO 14.000. Disponível em: <https://www.iso.org/iso-14001-environmentalmanagement.html>. Acesso em: 13 out. 2016.

KIRTON, John; TREBILCOCK, Michael. Hard choices, soft law: voluntary standards in global trade, environment and social governance. Aldershot: Ashgate, 2004.

KOERNER, Andrei. Direito. In: In: ARNAUD, André-Jean; JUNQUEIRA, Eliane Botelho (Org.). Dicionário da Globalização: Direito - Ciência Política. Rio de Janeiro: Lumen Juris, 2006.

$\mathrm{KOH}$, Harold Hongju. Transnational public law litigation. Yale Law Journal, v. 100, p. 2347-2402, 1991.

KUHN. Thomas S. A Estrutura das revoluções científicas. 3. ed. Tradução: Beatriz Vianna e Nelson Boeira. São Paulo: Perspectiva, 1994.

LAMBERT, Hélène. Transnational law, judges and refugees in the European Union. In: GOODWIN-GILL, Guy S.; LAMBERT, Hélène. The limits of transnational law: refugee law, policy harmonization and judicial dialogue in the European Union. New York: Cambridge University Press, 2010.

LUHMANN, Niklas. Sistemi sociali. Fundamenti di una teoria generale. Tradução: Alberto Febbrajo e Reinhard Schimidt. Bologna: Il Mulino, 1990.

LYOTARD, Jean-François. A condição pós-moderna. 9. ed. Rio de Janeiro: José Olympio, 2006.

MCGREW, Anthony. Globalization and territorial democracy: an introduction. In: MCGREW, Anthony (Ed.). The transformation of democracy? Cambridge: Polity Press, 1997.

MERRY, Sally Engle. Legal pluralism. Law \& Society Review, Beverly Hills, n. 22, p. 869-901, 1988.

MOREIRA, Vital. Auto-regulação profissional e administração pública. Coimbra: Almedina, 1997. 
MOSTACCI, Edmondo. La soft law nel sistema delle fonti: uno studio comparato. Padova: CEDAM, 2008.

NYE, Joseph S. Soft Power: The Means to Success in World Politics. New York, Public Affairs, 2004.

ORGANIZAÇÃO DAS NAÇÕES UNIDAS. Países-Membros da ONU. 2016. Disponível em: <https://nacoesunidas.org/conheca/paisesmembros/>. Acesso em: 16 out. 2016.

OST, François. Contar a lei: as fontes do imaginário jurídico. Tradução: Paulo Neves. São Leopoldo (RS): Editora Unisinos, 2004.

PAIXÃO, Liziane; BERTOLDI, Márcia Rodrigues. A importância do soft law na evolução do direito internacional. Revista do Instituto de Direito Brasileiro, Lisboa, v. 1, n. 10, p. 6265-6289, 2012.

PARDO, José Esteve. Prólogo. DERNACULLETA I GARDELLA, Maria Mercè. Autorregulación y derecho público: la autorregulación regulada. Barcelona: Marcial Pons, 2005.

PEROSA, Bruno. A emergência da governança socioambiental no mercado internacional de biocombustíveis. Tese (Doutorado) - Fundação Getúlio Vargas (FGV), São Paulo, 2012.

SHORE, Cris. Audit culture and illiberal governance: universities and the politics of accountability. Anthropological Theory, v. 8, n. 3, 2008.

SNYDER, Francis. Soft law e prassi istituzionale nella comunità europea. Sociologia dei diritto, 1993.

STAFFEN, Márcio Ricardo. Direito global: humanismo e direitos humanos. Revista do Mestrado em Direito da Universidade Católica de Brasília, Brasília, v. 10, n. 1, p. 178-208, jan./jun. 2016.

STAFFEN, Márcio Ricardo. Interfaces do direito global. Rio de Janeiro: Lumen Juris, 2015.

STELZER, Joana. O fenômeno da transnacionalização da dimensão jurídica. In: STELZER, Joana; CRUZ, Paulo Márcio (Org.). Direito e Transnacionalidade. Curitiba: Juruá, 2009, p. 15-54.

STIGLITZ, Joseph E. Globalização: como dar certo. Tradução: Pedro Maia Soares. São Paulo: Companhia das Letras, 2007. 
TAYLOR, Charles. Invocar a sociedade civil. In: TAYLOR, Charles. Argumentos filosóficos. Tradução: Adail Ubirajara Sobral. São Paulo: Loyola, 2000.

TEIXEIRA, Anderson Vichinkeski; KÖCHE, Rafael. Um direito sem estado? Direitos humanos e a formação de um novo quadro normativo global. Revista de Direito Internacional, Brasília, v. 10, n. 2, p. 86-100, 2013 .

TEUBNER, Gunther. As duas faces de Janus: pluralismo jurídico na sociedade pós-moderna. In: TEUBNER, Gunther (Org.). Direito, sociedade e policontexturalidade. Tradução: Bruna Vieira de Vicenzi. Piracicaba (SP): Unimep, 2005.

TEUBNER, Gunther. Constitutional fragments. Oxford: Oxford University Press, 2012.

TEUBNER, Gunther. Direito, sociedade e policontexturalidade. Tradução: Bruna Vieira de Vicenzi. Piracicaba (SP): Unimep, 2005.

UNIÃO EUROPEIA. Diretiva 2001/18 do Parlamento e do Conselho. Disponível em: <http://eur-lex.europa.eu/legal-content/PT/ TXT/?uri=LEGISSUM\%3A128130>. Acesso em: 16 mai. 2017.

UNIÃOEUROPEIA.Diretiva2009/28doConselho.Disponívelem: $<$ http:// eur-lex.europa.eu/legal-content/PT/ALL/?uri=CELEX:32009L0028>. Acesso em: 16 mai. 2017.

UNITED STATES OF AMERICA. United States Court of Appeals for the Ninth Circuit. Doe vs. UNOCAL. Disponível em: $<$ http://openjurist. org/395/f3d/932>. Acesso em 20 set. 2015>. Acesso em 20 set. 2015.

VARELLA, Marcelo D. Internacionalização do direito: direito internacional, globalização e complexidade. Tese apresentada para obtenção de livre-docência junto à Universidade de São Paulo. Universidade de São Paulo. Faculdade de Direito. São Paulo, 2012.

VEIGA, João Paulo Cândia; RODRIGUES, Pietro Carlos. Arenas transnacionais, políticas públicas e meio ambiente: o caso da palma na Amazônia, São Paulo, Revista Ambiente \& Sociedade, v. XIX, n. 4, out.dez. 2016.

VILLARY, Michel. La pensée juridique. Paris: LGDJ, 1960. 
ZAGREBELSKY, Gustavo. Il sistema costituzionale delle fonti del diritto. Torino, Giappichelli, 1984.

ZERILLI, Filippo M. The rule of soft law: an introduction. Focaal Journal of Global and Historical Anthropology, n. 56, 2010.

Artigo recebido em: 03/04/2019.

Artigo aceito em: 20/04/2019.

\section{Como citar este artigo (ABNT):}

CALETTI, L.; STAFFEN, M. R. A fragmentação jurídica e o direito ambiental global. Veredas do Direito, Belo Horizonte, v. 16, n. 34, p. 277 310, jan./abr. 2019. Disponível em: <http://www.domhelder.edu.br/revista/ index.php/veredas/article/view/1455>. Acesso em: dia mês. ano. 